\title{
Ludwik Rydygier - contributor to modern surgery
}

\author{
Radoslaw Pach ${ }^{1}$, Anita Orzel-Nowak ${ }^{2}$, and Thecla Scully ${ }^{3}$ \\ ${ }^{1}$ First Department of General and GI Surgery, Jagiellonian University, Krakow, Poland \\ ${ }^{2}$ Institute of Nursing, Faculty of Health Care, Jagiellonian University, Krakow, Poland \\ ${ }^{3}$ University Hospital North Staffordshire, Stoke-on-Trent, West Midlands, UK
}

\begin{abstract}
Modern surgery is usually considered to have begun in nineteenth century Europe. One of the most famous contributors to gastric cancer surgery was the Polish surgeon Ludwik Rydygier, born in 1850. He initiated new methods in several fields, such as gastrointestinal surgery, orthopedics, gynecology, and urology. He was the second surgeon in the world to perform an antral resection, which he carried out on November 16, 1880. The patient, a 64-year-old man, suffered from pyloric cancer and died 12 hours after the procedure as a result of postoperative shock. The next pyloric resection was performed by Billroth in Vienna in 1881. In the nineteenth century few gastric resections were performed for peptic ulcer. The first successful antral resection for gastric ulcer penetrating to the pancreas was also performed by Ludwik Rydygier, in 1881. For many years Rydygier advocated resection in the treatment of gastric ulcers, although it was considered too dangerous for benign disease. He eventually proposed four indications for gastric resection: antral cancer, gastric ulcer, perforated gastric ulcer, and bleeding ulcers. Another operation performed for the first time by Ludwik Rydygier was gastroenterostomy, in a patient with a duodenal ulcer. In the following years other types of partial gastric resection and total gastrectomy were introduced. In 1992 the Ludwik Rydygier Association was founded in Krakow to commemorate the achievements of and pay tribute to this great surgeon. The Eighth International Gastric Cancer Congress will take place in 2009 in Krakow, where Ludwik Rydygier built a new surgical clinic in 1889.
\end{abstract}

Key words Rydygier · Pyloric cancer - Gastric cancer · History

The humble task is passing the scientific output to the pupils, introducing them to the world of science, and inculcating them with the devotion to their discipline. The second and more noble one is participation in the devel-

Offprint requests to: $\mathrm{R}$. Pach

Sas-Zubrzyckiego 8/16, 30-611 Krakow, Poland opment of science. Not everyone has the ability to contribute to these two fields; happy one who is conspicuous at least in one of them.

Ludwik Rydygier, 1912

Modern surgery is usually considered to have begun in nineteenth century Europe. The most outstanding surgeon, sometimes described as the father of European surgery [1], was Bernhard Rudolf Konrad von Langenbeck - director of the Clinical Institute for Surgery and Ophthalmology at the Charité in Berlin. Many of the greatest surgeons in Europe were Langenbeck's pupils: Theodor Billroth, Carl Hueter, Friedrich von Trendelenburg, Jan Mikulicz-Radecki, and Ludwik Rydygier.

Ludwik Rydygier (Fig. 1), one of the most famous Polish surgeons, was born in 1850 in Dusocin in western Prussia (after the partitioning of Poland; the town is now in central Poland). His family had German roots, but Rydygier always emphasized his Polish nationality. $\mathrm{He}$ received his medical education in Greifswald, Strasbourg, Berlin, and Jena [2]. Ludwik Rydygier achieved his doctorate in 1874 with a thesis on the activity of carbolic acid ("Experimentelle Beitraege zur Lehre von der Wirkung der Carbolsaeure") - his mentor was Professor Carl Hueter. He was also mentored by Langenbeck, Luecke, Vogt, and Ried. In 1878 Rydygier gained a further qualification in surgery in Jena with a thesis on a new treatment method for prosthetic joints ("Eine neue Methode zur Behandlung von Pseudoarthrosen") [3]. He came to Chelmno, a town on the Vistula River, in 1879, and worked in his private clinic there for 8 years. During that time Rydygier implied no endorsement of the status quo in surgery and initiated new methods in several fields, such as gastrointestinal surgery, orthopaedics, gynecology, and urology. In addition, he established his position in the scientific world. In 1887 Rydygier - well-versed in contemporaneous surgery - was offered the position of 
professor at the Jagiellonian University in Krakow, the oldest university in Europe, founded in 1364. He succeeded Jan Mikulicz-Radecki at the Chair of Surgery and held the position for 10 consecutive years [4]. During his time in Krakow Rydygier advocated the building of a new modern surgical clinic. The construction of the new clinic was finished in 1889 and the offi-

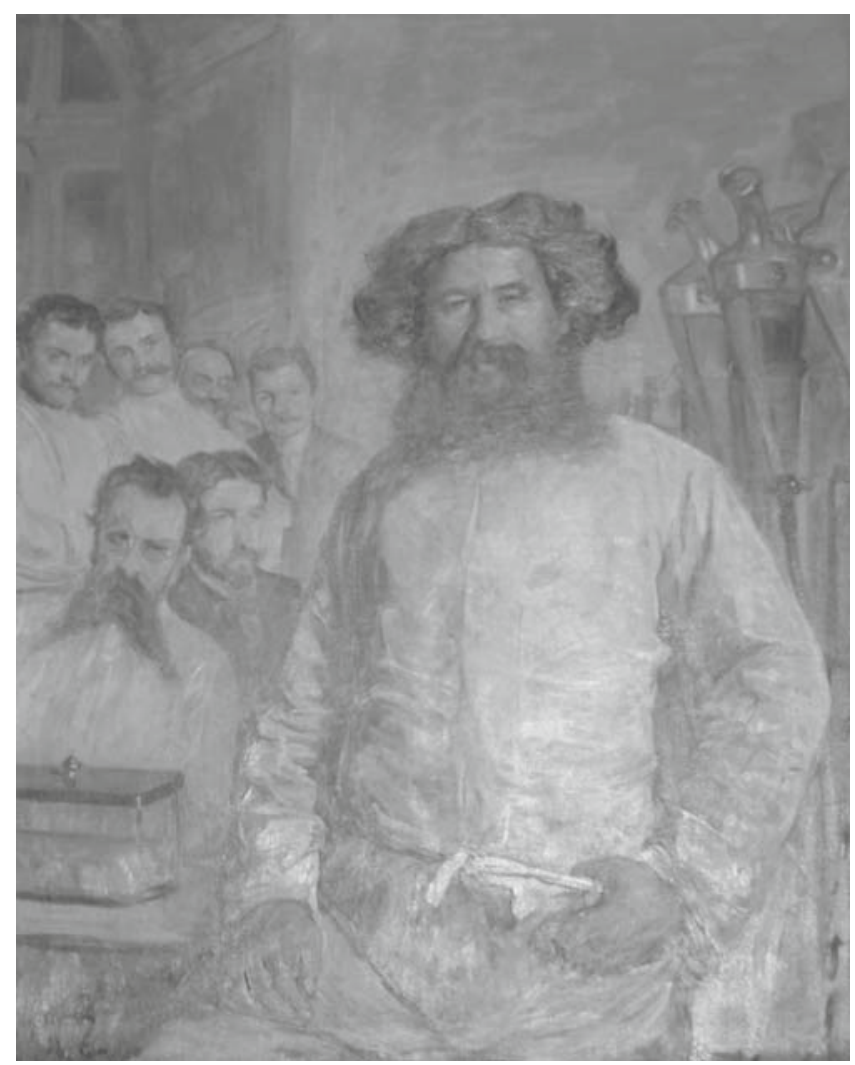

Fig. 1. Portrait of Ludwik Rydygier with assistants, painted by Leon Wyczolkowski cial opening came about on October 16 . This festivity was marked by the first meeting of the Polish Surgeons Society - an organization set up by this famous Polish surgeon. In appreciation of his activity, Rydygier was elected dean of the Jagiellonian University, Faculty of Medicine in the years 1888-1889. In 1890 he was awarded the Austrian Order of The Iron Crown, Third Class.

After 10 years Rydygier embarked on a journey to Lviv (now in Ukraine), where he remained until his death from a myocardial infarction in 1920. He became professor of surgery at the Jan Kazimierz University in Lviv held the position of dean twice, and was once elected rector magnificus (between the years 1901 and 1902). He was buried at Lyczakowski Cemetery; and later, his remains were moved to The Cemetery of the Defenders of Lviv.

The development of gastric surgery is an essential chapter in the history of medicine in nineteenth century Europe. The first man who had the courage to carry out a gastric operation was the French surgeon Jules Emile Pean [5]. He performed a pyloric tumor excision in Paris on April 9, 1879. The patient died 5 days after the procedure after two blood transfusions of 50 and $80 \mathrm{ml}$ [6]. Pean appraised the operation sceptically and did not publish the surgical technique details in the medical papers.

Ludwik Rydygier, after many years of experiments on animals, eventually decided to perform his first operation on a human. He performed an antral resection (Fig. 2), on November 16, 1880, in his private clinic in Chelmno. The patient, Julian Mikolajewicz, was a 64year-old man with a gastric neoplasm and a negative family history. He had been a trumpeter in the army and had later worked as a court clerk. The patient had suffered from vomiting for 5 weeks and physical examination revealed a palpable, movable solid tumor in the epigastrium. For 2 days before the surgery no oral diet
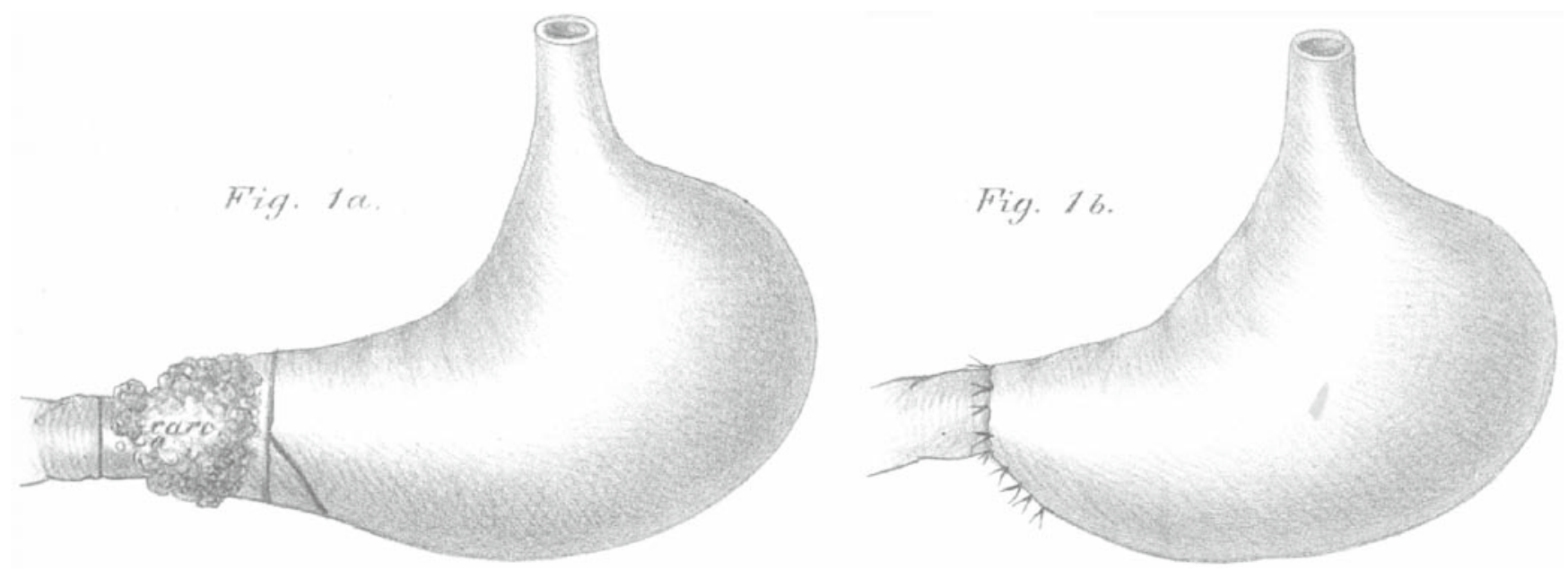

Fig. 2. The scheme of the pyloric resection in Julian Mikolajewicz, drawn by Ludwik Rydygier 


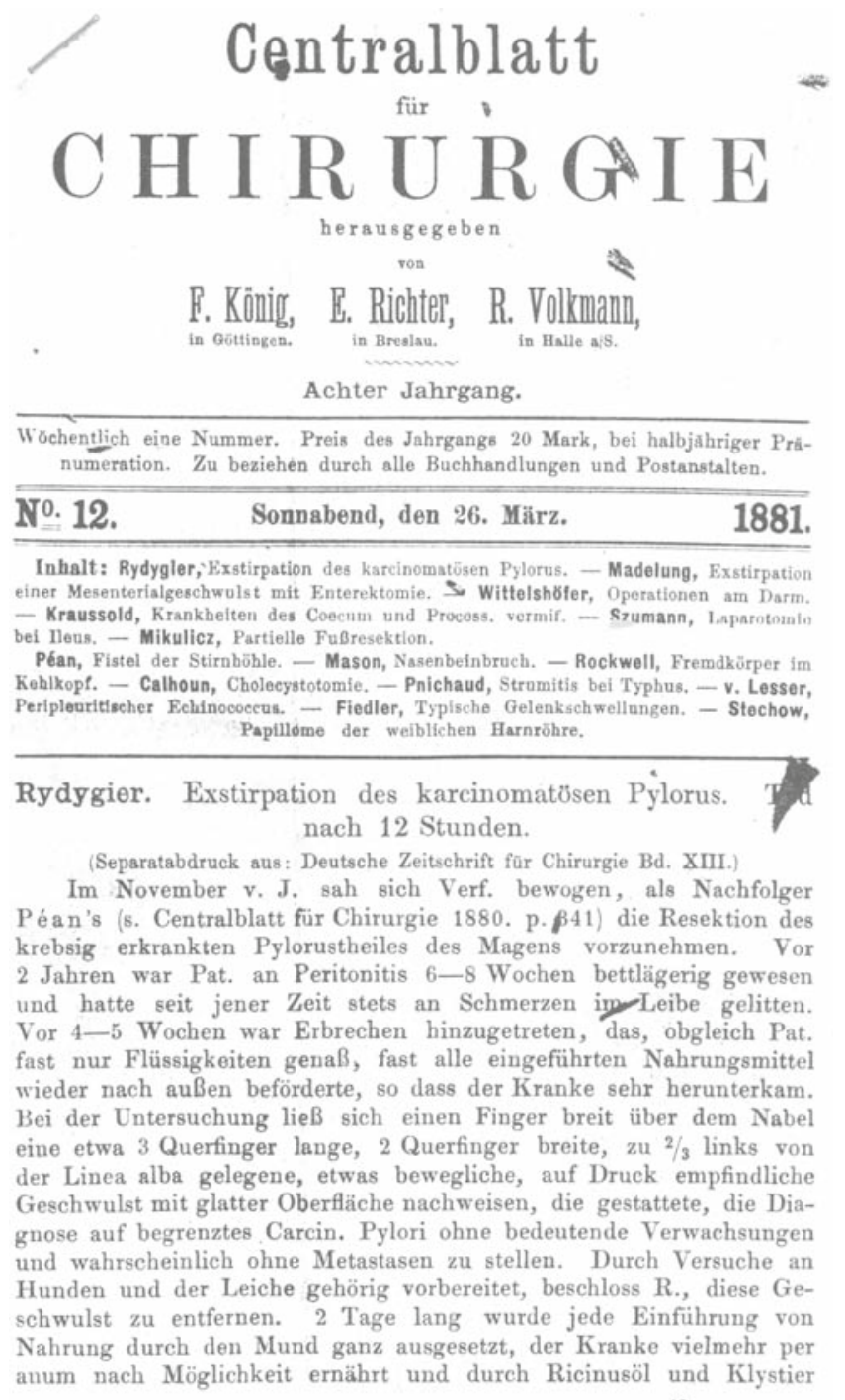

12

Fig. 3. First page of Rydygier's article in Centralblatt für Chirurgie in 1881, entitled: "Exstirpation des karcinomatosen Pylorus. Tod nach 12 Stunden (Excision of pyloric cancer. Death after 12 hours)"

was given. During the operation, which lasted 4 hours, Rydygier was assisted by Wehr, and there were three more witnesses of the procedure: Przeworski, Wiener, and Anderson. The patient died 12 hours after the procedure (at 4 a.m.) as a result of postoperative shock. Autopsy revealed no signs of peritonitis and showed a proper leakproof anastomosis. No signs of dissemination were observed. Rydygier published a detailed description of the pyloric resection in the Polish journal Przeglad Lekarski (December 11,1880) and later in the German journal Centralblatt für Chirurgie (March 26, 1881; Fig. 3). His publications provide deep insight into a then new surgical technique [7]. The Polish surgeon divided the procedure into five stages [8] — the first step was an abdominal wall incision from the xyphoid process to the umbilicus, with catgut sutures placed between the parietal peritoneum and the skin. The second stage consisted of a dissection of the antrum, blood vessel ligation, and clamping of the duodenum and the stomach (with elastic clamps made specially for that particular operation and invented by the surgeon himself). Next, resection of the antrum was performed, with the formation of a gastroduodenostomy (60 sutures were used for the anastomosis). Finally the abdominal wall was sutured.

The third surgeon who performed a successful resection for antral cancer was Theodor Billroth - the operation took place on January 29, 1881, in Vienna. Billroth announced his achievement in the form of an open letter in Wiener Medizinische Wochenschrift on February 2,1881 . The patient was a 43-year-old woman named Therese Heller; she was discharged 26 days after the operation and lived for another 4 months. She eventually died from a neoplastic dissemination (liver metastases). The surgical technique was quite similar in the two operations mentioned above. Billroth used a transverse skin incision above the palpable tumor (Rydygier, as previously stated, favored a midline incision) and did not use clamps - his assistants pressed the walls of the stomach and duodenum. Moreover, Billroth preferred silk sutures, whereas Rydygier used catgut ones (a total of 54 silk sutures were used by Billroth for the anastomosis). Billroth advocated stomach irrigation before surgical treatment (14l of water were used in Therese Heller) and cut the duodenum $2 \mathrm{~cm}$ below the tumor and the stomach $3 \mathrm{~cm}$ above the upper tumor margin [9]. Since the publication of his achievement Rydygier defended his victor's claim as a pioneer of gastric cancer surgery. Nevertheless, the question of priority in pyloric resection became the subject of a long-lasting dispute between Billroth and Rydygier [10].

In the nineteenth century few gastric resections were performed for peptic ulcer. The first successful antral resection for gastric ulcer penetrating to the pancreas was performed by Ludwik Rydygier in 1881 in Chelmno [11]. The patient's name was Karolina Pfenig. Her postoperative course was uneventful. Later the same procedure was carried out by Lauenstein, von Kleff, and Billroth. For many years Rydygier advocated resection in the treatment of gastric ulcers, although he was reproached for this, as resection was considered too dangerous for benign disease (in such cases gastroenterostomy was advised instead). Contemporary surgeons' grasp of this issue was insufficient, and finally in 1910, Kuettner and Payr backed Rydygier's idea and published a metaanalysis of 485 patients operated on for gastric ulcer, with a mortality of merely $10 \%$. Antral resection became the treatment of choice for gastric ulcers. Rydygier proposed four indications for gastric 
resection: antral cancer, gastric ulcer, perforated gastric ulcer, and bleeding ulcers.

The first Billroth II anastomosis was performed by Theodor Billroth and Victor Ritter von Hacker in 1885. The patient had a large pyloric tumor, so a gastric resection was carried out with closure of the gastric and duodenal stump. Then an anterior gastrojejunostomy was performed [12]. The entire cut end of the stomach was first used for antecolic anastomosis with the small bowel by Kroenlein in 1887. Eugen Alexander Pólya (Hungary) and Friedrich Paul Reichel (Germany) share fame for the introduction of a retrocolic gastrojejunostomy constructed in an end-to-side fashion after partial resection of the stomach (Billroth II-type) - this procedure was carried out in 1911 [13]. Partial gastrectomy with closure of a portion of the lesser curvature and retrocolic anastomosis of the remainder to the jejunum became associated with the name of Franz von Hofmeister, whose method was improved by Hans Finsterer. The division of the jejunum with anastomosis of the distal end to the stomach and proximal end to the jejunum below the gastroenterostomy was first performed by Anton Wölfer in 1893 and then propagated by Cesar Roux (the method now known as Roux-en-Y gastric bypass) [14]. The first successful complete gastrectomy was performed by the Swiss physician Carl Schlatter at the university clinic in Zurich in 1897 - this operation was reported in Bruns' Beiträge zur klinischen Chirurgie in 1903 [15]. His patient's name was Anna Zandis, a 56-year-old woman with diffuse gastric cancer. The postoperative course was favorable and the patient eventually died after several months from recurrent cancer. Soon total gastrectomy with end-to-side esophagojejunostomy was advocated for all gastric cancers.

Another operation performed by Ludwik Rydygier for the first time was gastroenterostomy, in a patient with a duodenal ulcer. The operation was carried out in 1884. The patient suffered from persistent vomiting and was primarily operated on for a suspected gastric ulcer. Intraoperatively, an obstructing duodenal ulcer was diagnosed and the abdominal cavity was closed. Rydygier decided to operate on this patient again because of recurring symptoms. A gastroenterostomy according to Wölfer (antecolic anterior gastrojejunostomy) was performed, although in those years the operation was indicated only for gastric and not for duodenal ulcer. During a conference of Polish surgeons in 1903 Rydygier compared three types of gastroenterostomy - according to Wölfer, Roux, and Brown. Wölfer's method was criticized due to one frequent manifestation of postoperative morbidity: transverse colon stenosis caused by an elevated small intestine loop.

As mentioned above, Rydygier contributed to the development not only of gastric surgery but also of cardiovascular, urological, and gynecological surgery.
He elaborated his own method for intussusceptions, treating excision of the prolapsed bowel by creating an aperture in the bowel into which the intestine was slid. Another one of Rydygier's crucial achievements was enteroenterostomy, after the removal of a part of the intestine (the first in Poland and fourteenth in Europe). He performed a laparotomy, excising approximately $6 \mathrm{~cm}$ of the intestine and anastomosing the endings with catgut sutures. Moreover, he suggested a definite operation in the case of an incarcerated hernia with bowel necrosis; he carried out 19 experiments on hounds to justify his proposal - two rows of sutures were used to close the intestine: deep furrier's sutures (piercing first one margin of the incision and then the other from within outward) and superficial, interrupted Lembert sutures (inverted sutures, laid through the serous and muscular tunics but not the submucosa, i.e., without having entered the lumen of the gut).

A new approach was proposed by Ludwik Rydygier for the diagnosis and surgery of rectal cancer. He recommended a digital rectal examination in all patients with rectal symptoms. The idea was that early diagnosis of carcinoma of the rectum may lead to a curative operation. He proposed that surgical access to the pelvic organs would be possible through a sacrococcygeal incision and temporary removal of the bones (a new method introduced by Rydygier; later, this technique was used in prostate cancer surgery). A frequent problem after rectal resection was anastomotic leakage due to intestinal necrosis. Rydygier advocated the formation of an artificial anus in the buttock and later, an iliac anus to prevent this serious morbidity.

Splenic surgery was also improved by Rydygier. For a floating spleen he introduced a method of splenopexy instead of the commonly performed splenectomy. The lower end of the spleen was fixed in a pocket formed between the parietal peritoneum and muscles; then it was stitched up with the peritoneum. Splenectomy was indicated only in advanced disease.

This famous Polish surgeon contributed to the development of esophageal surgery, too. He was the second surgeon to perform reconstruction of the esophagus according to Roux, in 1908. The procedure was carried out in a 25-year-old woman with cicatricial stenosis of the esophagus. The transplant (jejunum translocation to the anterior part of thorax) was viable, with proper peristalsis, but the patient died of severe pneumonia 5 weeks after the operation. Thus, Rydygier did not have the possibility of performing the last step of the operation, i.e., connection of the upper part of the intestine with the esophagus.

Many gynecological operations were performed by Ludwik Rydygier, especially during his stay in Chelmno. Among them, oophorectomy (3 cases), treatment of vesicovaginal fistulae (21 cases), and transvaginal 
hysterectomy (16 cases) deserve mention. In 1889 Rydygier ligated uterine and ovarian arteries in a 49year-old woman with genital tract bleeding. The operation resulted in immediate hemostasis and a $75 \%$ decrease in a uterine myoma mass after 4 months. Ultimately, the Polish surgeon changed this palliative, uncertain procedure to a hysterectomy with extraperitoneal ligation of the stump.

Some techniques introduced by Ludwik Rydygier to orthopaedics were also of substantial value. He invented a new method of prosthetic joint repair, recommended excision of two wedges from the tarsal bone in talipes varus, and proposed aggressive treatment of tuberculosis of the joints [16]. Better treatment results were seen after excision in the affected joint than after the conservative therapy used by contemporary physicians.

Although Rydygier made the most of innovations in medicine he did not believe in aseptic procedures. He denied the necessity of face masks, caps, and rubber gloves. On the contrary, he required hand disinfection (mechanical with water and soap, then plunging into an alcohol solution), mouth irrigation, gargling, and hairwashing before an operation. To prevent transmission of microbes to patients during operations, Rydygier constructed a special operating theater that students and other non-involved persons could not enter. This distinguished the operating room in Krakow from other crowded ones. The wound dressings were also changed in specially prepared rooms outside hospital wards. Rydygier operated slowly and precisely, and used a scalpel rather than scissors. Hemostasis was achieved using heavy pincers with clips. From his publications emerges the personality of a conscientious, keen investigator who supported all his results and conclusions with undisputed proofs. Every new idea was thought over and backed by strenuous laboratory experiments.

Ludwik Rydygier was the founder of a dynasty in which the fourth generation is still connected with surgery. His eldest son, Antoni, born in 1878, was a surgeon, too. He worked with his father, and after his parents' death emigrated to Brazil, where he became a professor at the University of Parana in Curitiba. Rydygier's grandson Ludwik worked as a surgeon in Curitiba for 45 years and had a son named Ricardo, who now holds the position of surgical professor at the University of Parana. Ricardo Rydygier visited
Krakow during the 100th meeting of the Polish Surgeons Society in 1989. In 1992 (July 29), the Ludwik Rydygier Association was founded in Krakow to commemorate the achievements of and pay tribute to this great surgeon [8]. This chapter of the organization awards outstanding surgeons and scientists with bronze and silver medals.

The Eighth International Gastric Cancer Congress will take place in 2009, in Krakow, where Ludwik Rydygier built a new surgical clinic in 1889 . The conference will be organized by the International Gastric Cancer Association (IGCA) and surgeons who work in the First Chair and Department of General and GI Surgery, Jagiellonian University.

\section{References}

1. Komorowski A, Wysocki W, Wysocki A. European surgical community: the unification of surgical science anticipated by German-Polish surgeons in the nineteenth century. Langenbecks Arch Surg 2004;389:234-6.

2. Moll J. Our surgical heritage. Ludwik Rydygier (1850-1920). Zentralbl Chir 1983;108:1532-5.

3. Popiela T, Legutko J. History of Polish gastrointestinal surgery. J Physiol Pharmacol 2003;54(Suppl 3):193-203.

4. Kucharz E, Shampo M, Kyle R. Ludwik Rydygier - famous Polish surgeon. Mayo Clin Proc 1991;66:1248.

5. Bary S. History of pylorus resection. Chirurg 1973;44:460-2.

6. Pean J. De l'ablation des tumeurs de l'estomac par la gastrectomie. Gaz Hop Civ Mil Empire Ottoman 1879;60:473.

7. Rydygier L. Ueber Magenresektion mit Demonstration von Praeparaten. Langenbecks Archiv für klinische Chirurgie 1881; 26:731.

8. Czupryna A, Orzel-Nowak A. Ludwik Rydygier zycie i dzielo (Ludwik Rydygier life and work). Krakow: Wydawnicto Ureus; 2005.

9. Santoro E. The history of gastric cancer: legends and chronicles. Gastric Cancer 2005;8:71-4.

10. Komorowski A, Wysocki W, Roviello F, Marreli D. Gastric resection Billroth or Rydygier? Chir Ital 2006;58:231-4.

11. Sablinski T, Tilney N. Ludwik Rydygier and the first gastrectomy for peptic ulcer. Surg Gynecol Obstet 1991;172:493-6.

12. Weil P, Buchberger R. From Billroth to PCV: a century of gastric surgery. World J Surg 1999;23:736-42.

13. Petri G. Our surgical heritage: the tragic destiny of the surgeon. Eugen Alexander Pólya (1876-1944). Zentralbl Chir 1985;110: 46-52.

14. Casal M. Cesar Roux and his Roux-en-Y anastomosis. Acta Gastroenterol Latinoam 1993;23:175-85.

15. Schlatter C. Über Ernährung und Verdauung nach vollständiger Entfernung des Magens, Oesophagoenterostomie, beim Menschen. Bruns Beitr Klinischen Chir 1899;23:589-94.

16. Dziak A. Ludwik Rydygier's activities and meritorious service in orthopedics. Chir Narzadow Ruchu Ortop Pol 1976;41:581-6. 